\title{
El principio de solución pacífica de controversias como norma de ius cogens en el Derecho Internacional
}

\section{The principle of peaceful settlement of disputes as a rule of ius cogens in International Law}

Miguel Ángel Rodríguez Mackay* http://dx.doi.org/10.21503/lex.v11i12.21

\footnotetext{
Decano de la Facultad de Derecho, Ciencia Política y Relaciones Internacionales de la Universidad Tecnológica del Perú. Miembro de la Sociedad Peruana de Derecho Internacional. Miembro de Número de la Academia Interamericana de Derecho Internacional y Comparado.
}

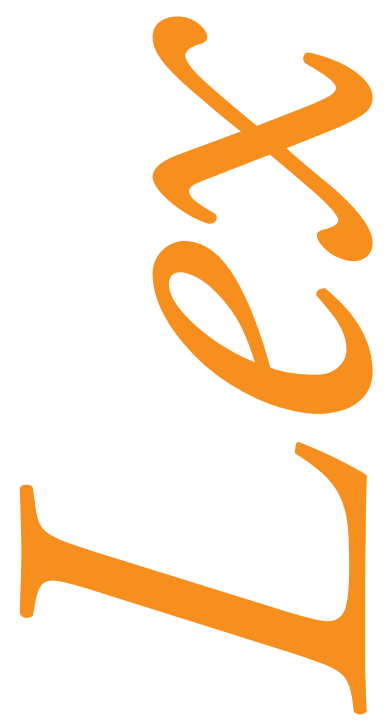




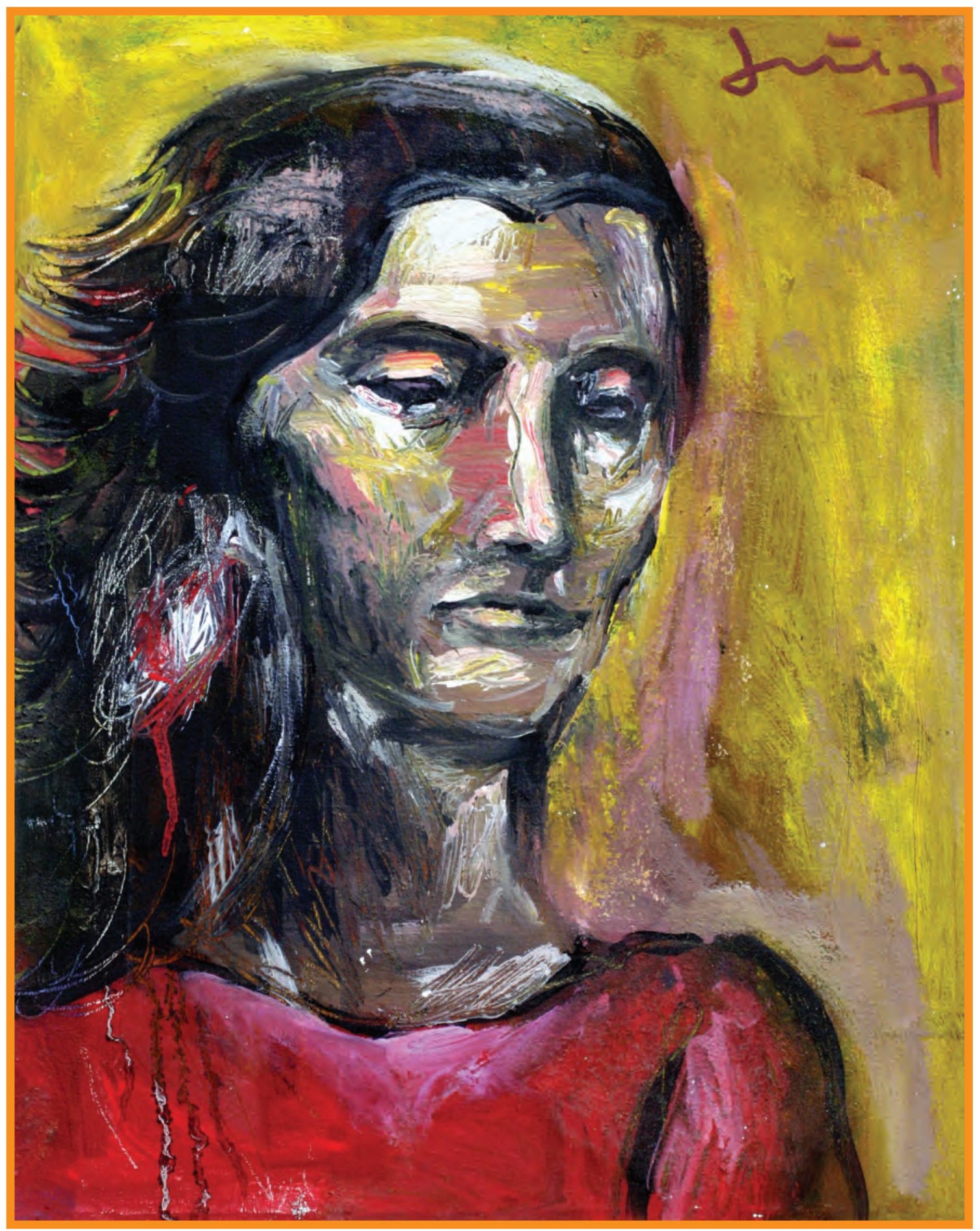

Violeta. 


\section{RESUMEN}

El presente artículo analiza el Principio de solución pacífica de controversias como norma de ius cogens en el Derecho Internacional. Este es uno de los principios más importantes del Derecho Internacional. Se propone una interpretación personal, en sintonía con las tendencias académicas propia de la disciplina de las Relaciones Internacionales y el Derecho Internacional. Estamos seguros que este artículo servirá de apoyo referencial de formación a todos aquellos que estén vinculados a la diplomacia, a las Relaciones Internacionales, el Derecho Internacional, que les permita entender mejor el mundo profundamente interrelacionado en que hoy vivimos y convivimos. Los conflictos son parte de la naturaleza del ser humano; por ende, un Estado no es ajeno a esta realidad. De allí que se trata de hacer una valoración académica de este principio que no hace más que enaltecer y reafirmar la moralidad mínima que se requiere en la comunidad internacional para vivir bajo un marco de concordia y de respeto estricto a lo que las partes suscriben.

Palabras clave: Derecho Internacional, ius cogens, solución pacífica de controversias.

\section{ABSTRACT}

This article analyses the principle of peaceful settlement of disputes as a rule of ius cogens in International Law. This is one of the most important principles of International Law. Personal interpretation is proposed in line with academic trends of the discipline of the International Relations and International Law. We are sure that this article will serve as referential support of training to all those who are linked to the diplomacy, to the International Relations, International Law allowing them to better understand the deeply interconnected world in which today we live together. Conflicts are part of the human being's nature; hence, a State is not immune to this reality. From there that is making an academic assessment of this principle which it doesn't do but elevate and reaffirm the minimum morality that requires in the international community to live under a framework of harmony and strict respect to what the parties hereto.

Key words: International Law, ius cogens, peaceful settlement of disputes. 



\section{INTRODUCCIÓN}

Abordar un análisis sobre el Principio de la solución pacífica de controversias como norma de ius cogens en el Derecho Internacional constituye un agradable momento para compulsar opiniones respecto a la importancia que significa este principio del Derecho Internacional Público. Se trata de un principio de aplicación erga omnes para todas las naciones civilizadas que abrazan al Derecho Internacional como una disciplina jurídica que limita y ordena la anarquía del propio sistema internacional, y promociona un orden axiológico sobre el sistema, común a todos los sistemas de Derecho. Parte de la realidad sobre el sistema internacional, es que es inestable y, esa inestabilidad conlleva al conflicto. El Derecho es, primordialmente, vida y no fundamentalmente norma, por tanto las controversias están presentes en la vida internacional, y esta es una característica propia de las relaciones internacionales entre unidades políticas organizadas.

\section{ASPECTOS GENERALES DEL DERECHO INTERNACIONAL PÚBLICO Y SU VINCULACIÓN CON LAS CONTROVERSIAS INTERNACIONALES}

Como sabemos, el Derecho Internacional Público es una disciplina jurídica problemática, dado por la carencia de instituciones que motivan la incertidumbre internacional. No existe en la Sociedad Internacional un órgano supremo legislativo que imponga a los Estados una determinada forma de conducta. Si bien es cierto que existen las Naciones Unidas (N.U.), que tiene un órgano plenario y deliberante como la Asamblea General ( A.G.), esta solo emite Resoluciones y Recomendaciones, pues tales resoluciones no son obligatorias para los Estados miembros. En otras palabras, no existe en la Sociedad Internacional un órgano normativo centralizado. Por tanto son los Estados — sujetos clásicos y primarios de Derecho Internacional— quienes crean el Derecho Internacional y son ellos mismos sus principales destinatarios.

Todo fenómeno jurídico va unido a una base social donde esta opera, su estructura, sus valores, sus normas, objetivos, etc. Es en este contexto donde se refleja el ordenamiento 
jurídico y se aplica. Lo mismo ocurre con el Derecho Internacional, porque es la Sociedad Internacional la base del Derecho Internacional.

Respecto al término de Sociedad Internacional y el término Comunidad Internacional, hay que precisar un punto interesante. Respecto a los términos sociedad y comunidad internacional, creo que el término "sociedad" es más adecuado para describir el estudio de las Relaciones Internacionales y el Derecho Internacional. La diferencia entre ambos conceptos fue establecida por el sociólogo alemán Ferdinand Tönnies en su obra Comunidad y sociedad (Gemeinschaft und Gesellschaft, 1887), donde marca límites entre una entidad natural (comunidad) y una artificial (sociedad). Por ejemplo, la comunidad islámica, que es una comunidad natural con una doctrina religiosa y legal particular, puede bien coexistir en la Sociedad Internacional y buscar acuerdos políticos, económicos, sociales, culturales, con otras comunidades distintas a ellas, y juntas describen el panorama de estudios de las Relaciones Internacionales que es la Sociedad Internacional. Bajo esta premisa de Sociedad Internacional es que posibilitó en el siglo XX la coexistencia entre dos mundos distintos como el comunismo y el capitalismo, sin que ambos lleguen a destruirse.

Así, el Derecho Internacional se ha configurado de distinta manera a razón de diferentes unidades culturales que se interrelacionaban y, establecían así un sistema propio de normas. Siendo que el requisito material para la existencia del Derecho Internacional es la coexistencia pacífica de entes políticos organizados sobre una base territorial, no subordinados a ninguna autoridad superior, pues, del Derecho Internacional podemos deducir que, sobre esta inestabilidad o anarquía propia del sistema internacional, es necesario crear un conjunto de normas y principios que formen el ordenamiento jurídico de la Sociedad Internacional, y esa es la creación de la disciplina del Derecho Internacional Público.

Pero lamentablemente la Sociedad Internacional no es homogénea, ni lo es ya estatocéntrica, es cambiante. Los Estados soberanos tienen poder y, muchos de ellos, sus comportamientos son más políticos que jurídicos y, eso representa la inestabilidad en el sistema. De todo lo dicho y de este carácter problemático, no puede decirse que la concepción del Estado de Derecho o principio de la Ley (Rule of Law) exista en la Sociedad Internacional en su conjunto.

A pesar de este panorama negativo, la evolución del pensamiento humano a lo largo de la historia ha establecido ciertas reglas de comportamientos que son imprescindibles para guardar la concordia entre todos los Estados del planeta. Recordemos que donde hay Sociedad hay Derecho y, donde hay Derecho, supone la existencia de una sociedad civilizada que acata reglas debidamente establecidas en el seno del grupo. Es así que, en estándares mundiales, el Derecho Internacional ha logrado alcanzar niveles de observancia y acatamiento importantes como: respeto a la Soberanía, cumplimiento de los tratados - y esto conecta con el principio 
del cual más adelante trataré-, cumplimiento de las normas sobre misiones de los agentes diplomáticos, etc. Pero otra cosa sucede con los intereses en el juego político de los Estados.

Para el profesor Pastor Ridruejo, ${ }^{1}$ el Derecho Internacional tiene una triple aproximación para determinar su concepto:

- Aproximación técnico-jurídica: intenta definir al D.I., donde su sistema normativo general son un Derecho Positivo, obligatorio a todos.

- Aproximación axiológica: fundamenta los valores; tiende a la protección de los valores de la persona humana.

- Aproximación histórica- sociológica: fundamenta cada etapa histórica de la Sociedad Internacional.

De manera que estas tres aproximaciones postulan a definir al Derecho Internacional ${ }^{2}$ como una disciplina metodológica interdisciplinaria, que no solo se limita a lo jurídico, sino a utilizar otras ramas del saber humano. Esta metodología interdisciplinaria que, junto al análisis científico, toma en cuenta la historia de las realidades sociales, políticas, económicas, tecnológicas, geográficas, culturales, pues nos ayudan a crear, modificar o extinguir normas internacionales de aplicación general.

Otra definición del D.I. es la que nos trae el profesor Suy, ${ }^{3}$ quien señala tres categorías para definirlo.

- Por sus destinatarios: el D.I. regulan las relaciones entre los Estados.

- Por su sustancia: el carácter internacional de esas relaciones reguladas.

- Por su técnica de creación de reglas Internacionales y su positivación.

De acuerdo con los principios constitucionales del D.I. y, aquí me voy a referir a su vinculación con la solución de controversias, la Sociedad Internacional se caracteriza por su naturaleza cambiante, compleja, heterogénea y poco integrada así como el estar sometida a un ordenamiento jurídico. ¿Cómo es posible someter una realidad social como esta a un cierto orden jurídico que otorgue la necesaria coherencia y estabilidad a la producción y cambio de las normas que regulan las relaciones en su seno? Se precisa la presencia de un amplio consensus sobre el marco general de referencia legal que dé soporte formal al proceso

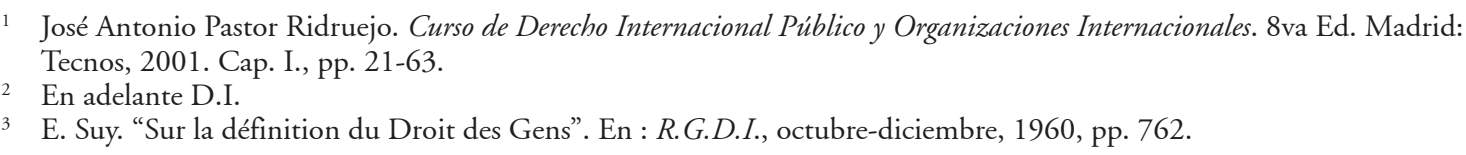


de formación y cambio de las normas en un contexto material como el del grupo social internacional marcado por las grandes desigualdades entre los Estados.

El origen de ese marco general de referencia son los principios formulados en el art. 2 de la Carta de las Naciones Unidas. Se trata de reglas de carácter general que pretenden enmarcar jurídicamente el comportamiento de los órganos de la O.N.U. y las relaciones entre los Estados miembros:

1. La Organización está basada en el principio de igualdad soberana de todos sus miembros.

2. Los miembros de la Organización cumplirán de buena fe las obligaciones contraídas por ellos de conformidad con esta Carta.

3. Los miembros de la Organización arreglarán sus controversias internacionales por medios pacíficos de tal manera que no se pongan en peligro la paz y la seguridad internacionales ni la justicia.

4. Los miembros de la Organización se abstendrán de recurrir a la amenaza o al uso de la fuerza contra la integridad territorial o la independencia política de cualquier Estado, o en cualquier otra forma incompatible con los Propósitos de las Naciones Unidas.

5. Los miembros de la Organización prestarán a esta toda clase de ayuda en cualquier acción que ejerza de conformidad con esta Carta, y se abstendrán de dar ayuda a Estado alguno contra el cual la Organización estuviere ejerciendo acción preventiva o coercitiva.

6. La Organización hará que los Estados que no son miembros de las Naciones unidas se conduzcan de acuerdo con estos principios en la medida que sea necesaria para mantener la paz y la seguridad internacionales.

7. Ninguna disposición de esta Carta autorizará a las Naciones Unidas a intervenir en los asuntos que son esencialmente de la jurisdicción interna de los Estados.

Recordemos que durante el desarrollo de la segunda mitad del siglo XX, para ser más específicos, la guerra fría impidió el desarrollo de estos principios hasta que se aprueba solemnemente por consenso la famosa Res. 2625, del 24 de octubre de 1970. La Res. 2625 declara y desarrolla normas del D.I. incluidos en la Carta como el principio de igualdad soberana de los Estados; el principio de buena fe; el principio de arreglo pacífico de las controversias; el principio de la prohibición de amenazar o del uso de la fuerza y el principio de la igualdad de derechos y de la libre determinación de los pueblos.

A estos cinco principios hay que sumar el principio de la no intervención y el principio de la cooperación pacífica entre los Estados, que son en cambio privativos de la Resolución 2625 porque no aparecen recogidos taxativamente en la Carta. 
El inciso 3 del artículo 2 de la Carta de las Naciones Unidas atiende a la noción del conflicto.

La Sociedad Internacional comporta factores belígeros por el hecho mismo de ser sociedad interestatal. Su estado normal no es el de la paz social sino el del conflicto.

La situación se modifica cuando la Carta de la ONU impone a los Estados miembros (art. 2,3) una obligación de arreglo pacífico de sus controversias internacionales de modo que no pongan en peligro ni la paz y seguridad internacionales ni la justicia, y, por la extensión que permite el art. 2.6, tal obligación se impone también a los Estados no miembros como necesaria al mantenimiento de la paz y seguridad internacionales.

Esto equivale a reconocer que no es la ONU en cuanto Organización sino los grandes estados actuando a través de esa Organización los agentes directos en la solución del conflicto. Pero fuera incluso de ese marco quedan los conflictos que enfrentan directamente a las grandes potencias. En ellos la ONU es ineficaz, ya que, por definición, entre grandes potencias no hay tercero posible en el plano de las realidades internacionales.

\section{LA INSTITUCIÓN DEL IUS GOGENS, EL PACTA SUNT SERVANDA Y LA SOLUCIÓN PACÍFICA DE LAS CONTROVERSIAS INTERNACIONALES}

Como he mencionada líneas atrás, el D.I. tiene como objetivo final de su fundamento que, bajo su estructura científica, permita una convivencia y coexistencia pacífica entre las diversas unidades internacionales que operan en el escenario mundial. Resulta sumamente importante que los Estados no solamente arreglen sus controversias utilizando los diferentes mecanismos que el Derecho Internacional les ofrece, sino también que se comprometan a cumplir de buena fe las resoluciones de los tribunales o alguna herramienta de solución pacífica de controversias recogidas en el mismo tratado que pudiesen suscribir.

Siendo así, el plano normativo del D.I. se conecta con el mundo de los valores e ideales que enriquecen la justicia y su promoción y extensión por el mundo. La paz es única aquí, y en cualquier otro lado del mundo. Valores que se conectan con el tema de los derechos humanos, el principio de la libre determinación de los pueblos, la noción del ius cogens, etc. Esto da buena fe a la existencia de esos valores; es el plano metafísico de la disciplina.

Entonces, el D.I. al estar dotado de valores y principios recogidos de la realidad de los diversos grupos humanos que se juntaron y dieron configuración al Estado libre, independiente y soberano, va formando las reglas de aplicación general y positivizando su aplicación general, lo que permitirá tener reglas jurídicas que tenga como fin la coexistencia pacífica de las diversas comunidades internacionales. En el mundo, no todas comunidades tienen los mismos valores ni las mismas creencias (comunidad islámica, comunidad de la India, etc.), pero sí hay ciertos principios y valores de observancia horizontal para preservar interrelaciones pacíficas. 
De lo anterior, es que nace la necesidad social o comunitaria de crear la institución del ius cogens, una institución del D.I. Algunos autores encuadran a esta institución en el grupo de las normas de orden público. Yassen señaló:

“(...) El único criterio admisible es la sustancia de la regla; para ser considerada como ius cogens, una regla de Derecho Internacional debe no solamente ser aceptada por un gran número de Estados, es necesario que ella esté anclada en la conciencia internacional". ${ }^{4}$

No cabe duda entonces que, el ius cogens está conectado con las reglas de orden público, ya que estas suponen salvaguardar los intereses del Estados, la sociedad. Es el cimiento jurídico que sostiene el ordenamiento material y moral de estos entes.

El término ius cogens o sus equivalentes, Derecho necesario, ius strictum, etc, suscitan de inmediato la idea de normas dotadas de una particular fuerza de obligar que se imponen como un Derecho necesario, frente a otras reglas que tienen carácter de Derecho dispositivo. Pero esta distinción entre diferentes clases de imperatividad entre las reglas jurídicas no es evidente por sí misma, ya que en eso consiste la esencia del Derecho: en que los mandatos de sus normas son constitutivos de obligaciones de cumplimiento necesario, no abandonado a la buena voluntad o parecer de los destinatarios de tales normas.

La Convención de Viena sobre el Derecho de los Tratados de 1969 dice en su artículo 53:

"La norma imperativa de Derecho Internacional general es una norma aceptada y reconocida por la comunidad internacional de Estados en su conjunto, como una norma que no admite acuerdo en contrario y que solo puede ser modificada por una norma ulterior de Derecho Internacional General que tenga el mismo carácter."

Del mismo modo, el profesor Jiménez de Arrechaga sostiene que las normas que tienen carácter de ius cogens son normas sobre las cuales no se permiten acuerdos en contrario; ello está en la naturaleza intrínseca de la regla imperativa. ${ }^{5}$ Añade el profesor que el ius cogens es la contrapartida del ius dispositivum, ya que supone una limitación a la libertad contractual de los Estados, e implica la negación de la concepción voluntarista de los Estados.

Las características del ius cogens son:

Mustafa Yaseen. Anuario de la Comisión de Derecho Internacional. Vol. I. p.68.

5 Eduardo Jiménez de Arrechaga. Derecho Internacional Contemporáneo. Madrid: Tecnos, 1980, p. 81. 
a) Es una norma aceptada y reconocida por la comunidad internacional en su conjunto.

b) Es una norma imperativa que no admite acuerdo en contrario.

c) Solo puede ser modificada por una norma de la misma jerarquía.

d) Su violación no afecta a los demás Estados.

e) Es una norma que pertenece al Derecho Internacional General

f) Presenta un efecto erga omnes.

La Corte Internacional de Justicia también lo ha reafirmado en el caso Barcelona Traction. La sentencia contiene obligaciones de los Estados hacia la comunidad internacional en su conjunto, que determinan esas obligaciones con efecto erga omnes y que son derivadas del ius cogens.

"Estas obligaciones resultan en el Derecho Internacional contemporáneo, de la puesta fuera de la ley de los actos de agresión y genocidio, así como los principios relaticos a los derechos fundamentales de la persona humana, comprendiendo en ellos la protección contra la práctica de la esclavitud y la discriminación" ${ }^{6}$

Carrillo Salcedo sostiene que los principios de D.I. tienen carácter de ius cogens, ya que contienen el mínimo jurídico esencial para la vida en armonía de la comunidad internacional, así como la moralidad internacional que debe existir. ${ }^{7}$

De lo dicho podemos decir que el ius cogen hace referencia directa a los principios básicos que la sociedad civilizada puede abrazar con total conciencia. Esto es importante observar ya que también se conecta con el principio del Pacta Sunt Servanda. Es importante señalar que todo tratado contrario a una norma de ius cogens será nulo.

Los Estados suelen, en virtud de la aplicación de su política exterior, utilizar los instrumentos del Derecho Internacional para determinar sus objetivos exteriores. Dichos instrumentos son los tratados. Los tratados son acuerdos que suscriben los Estados, y que comportan todo un acuerdo formal entre dos Estados o más Estados u otros sujetos internacionales, además de establecer derechos y obligaciones entre las partes contratantes. La Convención de Viena de 1969 dice en su art. 2. :

CIJ. 1970, p.31.

J. A. Carrillo Salcedo. Soberanía del Estado y Derecho Internacional. Madrid: 1976, pp. 284-285. 
"es un acuerdo internacional celebrado por escrito entre dos Estados y regido por el Derecho Internacional, ya conste en un instrumento único o en dos o más instrumentos conexos y cualquiera que sea su denominación particular".

Este amplio concepto incluye acuerdos entre Estados y Organizaciones Internacionales, y entre estas recíprocamente.

El profesor Wieland Alzamora rescata algunas distinciones sobre el término tratado. Señala: "Los criterios para determinar si un compromiso, un acuerdo oral, un documento o juego de documentos, incluido un intercambio de notas o correspondencia, constituye un acuerdo internacional, han sido definidos por el Departamento de Estado norteamericano y merecen citarse como una clara indicación de las cuestiones implicadas. Estos criterios son: primero, la identidad e intensión de las partes. Una parte en un acuerdo internacional debe ser un Estado, agencia estatal o una organización intergubernamental, y las partes, por lo menos dos, deben tener la intención de que el compromiso sea jurídicamente obligatorio y no lo inspiren solo propósitos políticos o morales". 8

Para la doctrina ius cogens, se citan hoy como reglas más características:

a) La prohibición de la esclavitud.

b) La prohibición del uso de la fuerza de modo contrario a los principios de la Carta de las Naciones Unidas.

c) El delito de agresión.

d) La discriminación racial.

e) La prohibición del trato inhumano o degradante.

Todas estas cuestiones que poco o nada tienen que ver con aspectos concretos de la contratación internacional, son normas que apuntan a la protección de valores fundamentales humanos o a la defensa de principios básicos de la comunidad internacional.

A esos ejemplos habrá que añadir determinadas normas estructurales que tienen relación directa con las formas esenciales de la sociedad internacional: principio de libertad de los mares y de las comunicaciones, concepción de la soberanía que ejercen los Estados como fuente no solo de derecho sino también de obligaciones, etc.

Ahora, luego de tener en cuenta estos aspectos importantes del Derecho Internacional y de la institución del ius cogens, me toca referirme al principio del Pacta Sunt Servanda. Dado que

8 Hubert Wieland Alzamora. Manual del Diplomático. Lima: Fondo de Cultura Económica, Academia Diplomática del Perú, 1999, p. 94. 
las normas del ius cogens se enmarcan dentro del grupo de principios observables para toda la comunidad en su conjunto, la misma lógica resulta para el principio del Pacta Sunt Servanda.

Tal como ha ocurrido en la antigüedad y, sobre todo en la configuración de la diplomacia, la doctrina romana de la validez de los contratos entrañaba una firme creencia en la santidad de los tratados; y la popularidad de la leyenda de Régulo, un hombre que sacrificó su vida antes de romper la promesa a los cartaginenses, muestra el arraigo del respeto a un acuerdo internacional, enfatiza la fidelidad a los compromisos, la concepción de principios de lo que ahora se llamaría conducta internacional. Los tratados deben poseer consideraciones de equidad y razón.

Este principio del Pacta Sunt Servanda proviene de la voz latina que significa "lo pactado obliga". En otras palabras, todo tratado debe ser cumplido por las partes contratantes de acuerdo con lo pactado. Los acuerdos internacionales son una fuente de D.I., pues estos crean derechos y obligaciones cuyo origen se conocen como derecho convencional, y tiene efecto jurídico de Tratado. Este principio es reconocido por la jurisprudencia internacional, es una regla sin oposición para los efectos del tratado. Pacta Sunt Servanda implica la buena fe que prevalece durante la ejecución del tratado suscrito en vigor, pues ello satisface una necesidad de seguridad jurídica.

Este principio data desde las épocas de la antigua Roma, donde los pactos se honraban, y la buena fe de esos contratos suponía la confianza que depositan los suscribientes. Es atribuido al jurista Ulpiano en el Digesto. En la antigüedad se habló del fundamento religioso de la inviolabilidad de los tratados; se pensaba en la sacralización de la norma, es decir, una norma sacrosanta. Los tratados debían respetarse porque Dios mismo es testigo, garante y juez de las obligaciones contraídas. El feudalismo y la caballería, en la Edad Media, invocaban la lealtad y el honor. En la Edad Moderna, se omite el carácter sagrado de la norma Pacta Sunt Servanda, y se aducen consideraciones jurídicas subjetivas y voluntaristas: costumbre, consentimiento, autolimitación y voluntad común.

Hans Kelsen le otorga una categoría consuetudinaria, es decir, que este principio surge de la costumbre, como un acuerdo tácito y que por lo mismo toma validez de un principio voluntarista.

Durante la formación de la comunidad de Estados Cristianos, que abarca desde el siglo XVI hasta la paz de Westfalia (1648), la monarquía se libera de los señores feudales y se afirma, gracias al ejército permanente, una autoridad nacional. ${ }^{9}$ 
En la actualidad, este principio se ha incorporado tanto en el Derecho Civil interno como en el Derecho Internacional, como principios importantes. Si una de las partes no cumple con lo pactado, es susceptible que la parte perjudicada pueda accionar jurídicamente para su cumplimiento o para ser indemnizada por daños y perjuicios que le fueron generados.

De los principios que rigen el sistema jurídico de los tratados, el más importante es el de la norma Pacta Sunt Servanda, que prescribe la obligatoriedad de los pactos. Este pacto puede equipararse al enunciado de Derecho Interno de que los pactos legalmente celebrados deben ser puntualmente exigidos. Se fija esta norma como el postulado importantísimo que alimenta no solo el Derecho Internacional, sino todo el sistema jurídico en su conjunto.

El artículo 26 de la Convención de Viena de 1969 establece:

"Todo tratado en vigor obliga a las partes y debe ser cumplido por ella de buena fe."

Observamos, así, que este criterio jurídico se refiere al principio del Pacta Sunt Servanda. Seguidamente, el artículo 27 de la citada convención establece que "una parte no podrá invocar disposiciones del Derecho Interno como justificación del cumplimiento de un tratado".

Observamos que los legisladores internacionales han puesto un límite a los Estados que no reconozcan este principio, amparándose en las disposiciones de su Derecho Interno.

El Pacta Sunt Servanda se encuentra ligado a la buena fe en la ejecución de los contratos, y se refiere a que no solamente las partes deben cumplir con lo estipulado, sino que deben hacerlo de buena fe, es decir, sin caer en el abuso de los derechos u obligaciones que le otorgan o imponen dichos instrumentos. También dicho principio es una norma general de carácter consuetudinario perteneciente al Derecho Internacional, dado que los Estados celebran tratados, y el respeto por esos pactos ha sido una costumbre generalizada en el tiempo. El principio de la buena fe es un principio legal que forma parte integral de la regla Pacta Sunt Servanda.

El principio del Pacta Sunt Servanda es un principio universalmente reconocido, reiteradamente evocado por la jurisprudencia arbitral y el Tribunal de la Haya, la Carta de las Naciones Unidas, las Convenciones sobre el Derecho de los Tratados de 1969, la Declaración sobre los Principios del Derecho Internacional referentes a las relaciones de amistad y a la cooperación entre los Estados.

En el plano universal, la Carta de las Naciones Unidas establece que el Pacta Sunt Servanda es el principio de D.I. que obliga a los Estados y a los otros sujetos del D.I. a respetar de buena fe los tratados celebrados y que han hecho entrar en vigor. Así, el consentimiento de las partes antecede al cumplimiento de los tratados y crea una norma de carácter imperativo, de carácter 
legal, que no puede ser desconocida por los Estados que los suscribieron. Este principio tiene una base objetiva y coercitiva, y se ampara en preceptos jurídicos así como en preceptos de la moral.

Como se ha mencionado anteriormente, para la convivencia pacífica entre las naciones es sumamente importante la observancia y el cumplimiento de este principio, ya que sin él, en el sistema opera una palpable anarquía sin tratados que no se cumplen. El Derecho Positivo de las partes contratantes así como las formalidades previstas para la suscripción de un tratado dan eficacia jurídica al principio del Pacta Sunt Servanda.

Dicho principio tiene una base moral indiscutible. La moral social -Derecho Natural - vinculada con el principio de Pacta Sunt Servanda — que es la evolución de la teoría del consentimiento- se constituye en una base positiva y filosófica. Es el binomio de consentimiento y socialización que explica la vigencia del D. I. El Derecho Natural establece que los principios de D.I. se centran en dos normas fundamentales: la obligación de cumplir los acuerdos pactados y el deber de reparar el daño causado ante su incumplimiento. Por encima de este principio está la idea de la justicia que reposa sobre la conciencia jurídica de los hombres y el carácter obligatorio de sus normas.

Si bien es cierto que la historia nos ha demostrado numerosos ejemplos de incumplimientos de obligaciones solemnes, inclusive hoy en día, sin embargo, estas circunstancias desafortunadas no afectan la validez del principio del Pacta Sunt Servanda.

El Embajador Óscar Maúrtua de Romaña ${ }^{10}$ nos recuerda que los esfuerzos de codificación fueron realizados en un proyecto de la Universidad de Harvard en 1935, y fue la Comisión de Derecho Internacional de las N.U. la que dio luz en 1969 a la Convención de Viena sobre Derechos de los Tratados, instrumento sobre el cual contempla este principio en su artículo 26. De igual modo, según el art. 18 de la citada Convención, el efecto jurídico del principio se extiende, hasta cierto grado, a los tratados que han sido firmados pero que aún no han sido ratificados o aprobados por su respectivos cuerpos legislativos.

Para Lewis Coser, el conflicto se caracteriza por ser la lucha o reclamo para obtener valores, estatus, poder o recursos en los cuales los objetivos de las partes son neutralizar, herir o eliminar a sus rivales. ${ }^{11}$

El Diccionario de la Real Academia de la Lengua Española define al conflicto como "el punto en que aparece incierto el resultado de una pelea”. ${ }^{12}$

10 Óscar Maúrtua de Romaña. "Pacta Sunt Servanda y la solución de controversias". Rev. ADP, No 37, julio-setiembre, Lima, 1994.

11 Lewis Coser. Las funciones del conflicto social. México: Fondo de Cultura económica, 1961

12 Real Academia Española. Diccionario de la Lengua Española. 19a edición. Madrid: Editorial Espasa-Calpe, 1970. 
Respecto a la solución pacifica de las controversias como norma de ius cogens en el Derecho Internacional, los Estados en su conjunto quedan emplazados, en virtud del art. 2 inc. 3 de la Carta de la ONU, a recurrir a medios pacíficos para resolver los conflictos que pudiesen generarse como producto de sus interrelaciones.

El espíritu del principio de la solución pacífica de controversias internacionales podemos encuadrarlo en la categoría del ius cogens, por dos razones. Primero, porque el fundamento del Derecho Internacional nació para regular relaciones jurídicas de la sociedad internacional en general, y esa regulación apunta a la finalidad de que los Estados puedan vivir y convivir en armonía. Y segundo porque ese principio reposa sobre una base axiológica, dado que el ius cogens abraza principios de carácter de moral internacional, la paz y su solución como medio. Refleja y reafirma la importancia de este principio para su aplicación erga omnes en las naciones que aplican la razonabilidad (razón + habilidad) para solucionar sus controversias de manera ejemplar.

Sí alejáramos el valor supremo de la paz, revestido jurídicamente en el principio de la solución pacífica de controversias internacionales, la noción del conflicto sería mucho más notoria sobre el propio sistema internacional anárquico, sin mecanismos jurídicos, ni aspectos de la moralidad internacional que nos recuerden que el objetivo último de todos los Estados, además del propósito que inspiró a la creación de las Naciones Unidas después de los horrores de las segunda guerra mundial, sea precisamente el de la paz y la seguridad internacional. Para ello, las naciones civilizadas amantes de la paz, apelando a esa moralidad internacional, le han otorgado a la Corte Internacional de Justicia el honorable trabajo de resolver jurídicamente las controversias que se puedan originar. También debemos recordar que los mismos Estados pueden elegir otros medios pacíficos para resolver sus conflictos como el arbitraje internacional, conciliación o jurisdicciones creadas a partir de un tratado internacional como el Pacto de Bogotá de 1948 o el espíritu que sigue la UE para someter sus controversias en el seno mismo de su organización, como el Tribunal de Justicia de la UE.

El conflicto es parte de la realidad internacional. ¿Puede el conflicto ser un acto político? En el libro Vom Kriege (De la guerra), de Carl von Clausewitz, afamado militar prusiano, se lee que "la guerra es un acto político". Clausewitz ${ }^{13}$ concebía la guerra como una empresa política de alto vuelo, sin desconocer la brutalidad que implica; consideraba que todos los recursos de una nación deben ponerse al servicio de la guerra cuando se decide su ejecución. Y pensaba que la guerra, una vez iniciada, no debe detenerse hasta desarmar y abatir al enemigo.

13 fue un militar prusiano, uno de los más influyentes historiadores y teóricos de la ciencia militar moderna. Conocido principalmente por su tratado De la guerra, que consta de ocho volúmenes y es un análisis sobre los conflictos armados, desde su planteamiento y motivaciones hasta su ejecución, comentarios sobre táctica, estrategia e incluso filosofía. 
Su definición de la guerra es: "Constituye un acto de fuerza que se lleva a cabo para obligar al adversario a acatar nuestra voluntad”. De lo dicho, el sistema internacional contemporáneo, tomando como ejemplo los horrores de las dos guerras mundiales, ha ido generando espacios de dialogo para evitar, precisamente, el surgimiento de nuevas guerras mundiales, a través de medios pacíficos de solución de controversias.

Para Clausewitz la guerra no requiere crueldad, ni la política beligerancia. Alcanza con un fin que se contraponga a otro fin y un grupo de hombres a otro grupo de hombres, para que la seriedad de la vida se manifieste. Por tanto, en la actualidad, la globalización nos puede estar empujando a nuevos problemas y desafíos mundiales que pueden reflejarse en fines, oportunidades, amenazas, donde los actores internacionales contrapongan sus diferentes intereses de manera seria.

Como hemos dicho, ciertos actos u omisiones de los diferentes sujetos del Derecho Internacional pueden originar, en determinadas circunstancias, conflictos internacionales. Esta situación comporta tres tiempos importantes:

a) Determinar y analizar la situación que puede desembocar en una crisis, es decir, que se halla en un estado potencial.

b) Frente a la situación de crisis ya presente, la que refleja la tensión de dos intereses contrapuestos, se considera si es posible actuar uno contra el otro.

c) Cuando ya se originó la controversia, una de las partes hace valer frente a la otra su pretensión, para lo que puede recurrir a una demanda o al uso de la fuerza si lo cree necesario.

Estos tres momentos constituyen una crisis internacional. Los mecanismos de arreglo pacífico de controversias pueden funcionar en cualquier de los tres niveles, con el objetivo de prever e impedir que la situación se desarrolle y se convierta en una controversia.

El Tribunal Permanente de Justicia Internacional, antecesora de la Corte Internacional de Justicia, define a la controversia así:

"Una controversia es un desacuerdo sobre un punto de derecho o de hecho, una contradicción, una oposición de tesis jurídicas o de intereses entre dos personas". ${ }^{14}$

Actualmente, la CIJ en la sentencia de 1998 sobre el Asunto de la frontera terrestre y marítima entre Camerún y Nigeria declaró:

14 Asunto Mavrommatis de 1924. CPJI. Ser. A Nº 2, p.11. 
"Para establecer la existencia de una controversia hay que demostrar que la reclamación de una parte se enfrenta al rechazo manifiesto de la otra parte $\mathrm{y}$, además, que la existencia de dicha controversia se determine de forma objetiva". ${ }^{15}$

En sentido restringido, puede decirse que surgirá una controversia cuando una parte presenta a otra una reclamación basada sobre una presunta violación de la ley y esta la rechaza. ${ }^{16}$

Como vemos, una idea de la controversia refleja un desacuerdo entre dos sujetos de la comunidad internacional. Estos clásicamente corresponden a desacuerdos entre Estados, pero eso no quiere decir que no se considere también a las controversias sobre los desacuerdos surgidos entre un Estado y una Organización Internacional o entre dos organizaciones internacionales.

La controversia puede versar sobre cuestiones de Derecho o cuestiones políticas. No todas las controversias se resuelven en una corte internacional de carácter eminentemente jurisdiccional. Es importante señalar también que para que exista una controversia internacional hace falta que la misma se haya originado por las partes después de conversaciones directas u otros medios que ayuden a delimitar su contenido, para que la diferencia sea identificada objetivamente.

Hemos dicho que las controversias pueden ser jurídicas o políticas, dependiendo de si su solución requerirá de alguna modificación del Derecho vigente o de su simple aplicación. Toda controversia entre Estados reúne matices políticos y jurídicos.

En el contexto de la guerra fría, el concepto controversia adquiere características especiales; por ejemplo, la desintegración del antiguo bloque soviético originó la vuelta de viejos conflictos, como es el caso de los Balcanes; dichas controversias son originadas por una sociedad civil imbuida de factores étnicos, lo que genera en la comunidad internacional un desafío. Serbia debe ser el caso más representativo en el área de los Balcanes. En este contexto, se plantea a la comunidad internacional la responsabilidad de actuar ante la eventualidad de un conflicto masivo en la zona, la misma que originará una nueva revisión del concepto de controversia y la utilización de diferentes instrumentos internacionales para la solución de controversias.

De lo anterior, sobre los desafíos del presente siglo, ya existe una corriente desarrollada, académicamente, por la Universidad de Harvard por promover la intervención de organismos no gubernamentales como una posible solución a las controversias emanadas. El fondo de esta corriente académica no solo tiene como objetivo la adecuación de la legislación internacional

15 1998. Frontera terrestre entre Camerún y Nigeria, excepciones preliminares. Ver más en: Revista Electrónica Iberoamericana. http://www.urjc.es/ceib/ Vol. 6, No 2. 2012. Centro de Estudios Iberoamericanos.

16 Max Soresen (Editor). Manual de Derecho Internacional Público. México: Fondo de Cultura Económica, 1985, p. 628. 
a los nuevos fenómenos ya mencionados, sino que hay un evidente cuestionamiento respecto a la eficiencia de los organismos internacionales (Naciones Unidas, Cortes Internacionales), que se han visto influenciados por factores políticos en la toma de sus decisiones. Otros sostienen que la solución de controversias implica un trabajo especializado de negociación, mediación e incluso de arbitraje, alejando las sombras políticas a efectos de emitir un rápido y mejor acercamiento de las partes en conflicto.

\section{LOS SISTEMAS DE ARREGLO PACÍFICOS DE LAS CONTROVERSIAS INTERNACIONALES ${ }^{17}$}

\section{A) CONCEPTO DE DIFERENCIA}

En la Jurisprudencia Internacional encontramos un concepto de diferencia muy amplio y comprensivo. El TPJI la definió de la forma siguiente:

"Una diferencia es un desacuerdo sobre un punto de derecho o de hecho, una contradicción de tesis jurídicas o de intereses entre dos personas".

Esta definición puede adaptarse a las diferencias regidas por el DI, teniendo en cuenta que:

a) Las personas a que se refiere tienen que ser sujetos del Ordenamiento Internacional (Estados, OOII, etc.)

b) La diferencia supone una discrepancia entre las partes, no solo de cuestiones jurídicas, sino también de cuestiones de hecho, tales como límites entre dos Estados, el trazado de un punto concreto de la frontera, etc.

c) Para que exista una diferencia internacional, la misma tiene que haber sido fijada entre las partes mediante conversaciones directas, actos unilaterales, o cualquier medio que delimite su contenido y que objetivamente sea identificable.

En una concepción más estricta, la diferencia surge cuando un sujeto internacional hace valer ante otro una reclamación concreta basada en un incumplimiento de una obligación y la parte a la que va dirigida la rechaza.

El TIJ en una sentencia reciente señaló que para establecer la existencia de una diferencia hay que demostrar que la reclamación de una de las partes se enfrenta al rechazo manifiesto de la otra parte, y además debe determinarse de forma objetiva la existencia de la controversia.

17 José Omar Suclupe Añazco. Apuntes del Máster en Derecho Internacional y Relaciones Internacionales, dictado por el Instituto Europeo Campus-Stellae. Santiago de Compostela, España, 2012. 


\section{B) CLASES DE DIFERENCIAS}

Tradicionalmente, la mayoría de la doctrina ha distinguido:

- Diferencias jurídicas: las que son susceptibles de ser solucionadas aplicando el Derecho vigente.

- Diferencias políticas: las basadas en una pretensión cuya solución requiere una modificación del Derecho vigente.

Actualmente, esta distinción debe ser rechazada ya que toda discrepancia entre Estados, salvo casos excepcionales, reúne a la vez un matiz político y una dimensión jurídica. Se dice que las diferencias entre Estados tienen carácter mixto.

También se ha distinguido entre:

- Diferencias jurisdiccionales: cuando existe acuerdo entre las partes para someter la diferencia a arreglo arbitral o judicial.

- Diferencias no jurisdiccionales: cuando no existe este acuerdo.

Actualmente, ningún sujeto de DI puede ser sometido a un procedimiento de arreglo arbitral o judicial sin su consentimiento.

\section{C) LOS MEDIOS DE SOLUCIÓN DE DIFERENCIAS}

Tradicionalmente, se distinguían entre medios de solución pacíficos y medios no pacíficos. La razón es que hasta fecha reciente el uso de la fuerza era considerado como medio incluso lícito de arreglo. La obligación de resolver las diferencias por medios pacíficos es reciente dentro del D.I. y fue necesaria la llegada a nuestro siglo XX para que quedara configurada. En el Pacto de la Sociedad de Naciones se da un paso en el sentido de limitar la guerra. Así en el art. 12 del mismo se dice:

"Todos los miembros de la sociedad convienen en que, si surge entre ellos una diferencia susceptible de entrañar una ruptura, la someterán al procedimiento de arbitraje o a un arreglo judicial o al examen del Consejo. Convienen, además, que en ningún caso deberán recurrir a la guerra antes de la expiración de un plazo de tres meses después de la decisión arbitral o judicial o del informe del Consejo".

Otra clasificación de los medios de arreglo, que es la que sigue el Manual, distingue:

1) Medios diplomáticos o no jurisdiccionales. Son aquellos en los que intervienen los órganos normales de las relaciones internacionales: agentes diplomáticos, ministros de Asuntos 
Exteriores, etc. Se caracterizan porque no resuelven directamente la diferencia, sino que facilitan la solución mediante el acuerdo entre los Estados interesados.

Dentro de los medios diplomáticos encontramos:

- Las negociaciones diplomáticas.

- Los buenos oficios y la mediación.

- Las comisiones de investigación (investigación internacional).

- Las comisiones de conciliación (conciliación internacional).

2) Medios jurídicos o jurisdiccionales. Suponen que las partes se someten voluntariamente a un órgano judicial para que solucione la diferencia generalmente sobre la base del Derecho Internacional. La solución se contiene en una sentencia arbitral o judicial vinculante para las partes. Los medios jurídicos son el arbitraje y el arreglo judicial

Los sujetos internacionales tienen libertad de elección para solucionar la controversia internacional.

Este principio de libre elección de medios es el eje central de la Declaración de Manila sobre el arreglo pacífico de controversias internacionales, aprobada el año 1982.

\section{D) LOS MEDIOS LLAMADOS DIPLOMÁTICOS}

\section{a) Las negociaciones diplomáticas}

Constituyen el método más antiguo y más utilizado para el arreglo de diferencias. Consiste en el entendimiento directo entre las partes para solucionar una diferencia y llegar a un acuerdo sobre la misma. Esta relación directa se lleva a cabo mediante los servicios diplomáticos normales, o bien en el seno de una Conferencia Internacional.

Sus características son:

- Inmediatividad: conversaciones directas entre las partes.

- Rapidez: no se necesitan formalidades especiales.

- Pueden ser realizadas con gran discreción, incluso secreto.

Tiene un único límite: obligación de negociar de buena fe. Estas negociaciones se llevan a cabo por los métodos normales de la diplomacia: conversaciones directas, intercambio de notas diplomáticas, de propuestas, etc., y finalizan mediante declaraciones comunes o acuerdos entre las partes. 
Normalmente las negociaciones directas están previstas en los tratados de arreglos de diferencias como un medio previo a la vía arbitral o a la judicial. Pueden coexistir con otros medios de arreglo en una misma controversia.

\section{b) Los buenos oficios y la mediación}

Ambos métodos consisten en la intervención en el arreglo de la diferencia de un tercer sujeto internacional (Estado u Organización Internacional), o un grupo de ellos (mediación colectiva). Lo que distingue los buenos oficios de la mediación es la función del tercero.

Los buenos oficios. El tercero se limita a ser un simple intermediario, sin formular ninguna solución. Solo se intenta poner de acuerdo a las partes mediante una intervención discreta. Ejemplos: la actividad de la URSS en 1965 para favorecer el arreglo pacífico en la diferencia entre India y Pakistán con relación a Cachemira; o la de EEUU respecto de los Acuerdos de Camp David.

Cada vez es más frecuente que el Secretario General de las N.U. o sus representantes presten sus buenos oficios en las diferentes controversias internacionales.

La mediación. El mediador interviene proponiendo una solución, la misma que las partes no están obligadas a aceptar. Ejemplos: la mediación de Argelia en la controversia entre EEUU e Irán que desembocó en los Acuerdos de Argel; o la desempeñada por Nelson Mandela, antiguo Presidente de Sudáfrica, en el conflicto de Burundi en 1999.

Tanto los casos de buenos oficios como los de mediación no son muy frecuentes. No obstante, algunas organizaciones, como la ONU, han utilizado la mediación, pero no siendo la misma Organización la mediadora, sino personas particulares o funcionarios de las mismas.

La mediación puede surgir de la iniciativa de una tercera parte que propone interponerse y cuya oferta es aceptada por las partes en controversia. También puede ser directamente convenida por las propias partes.

\section{c) La investigación internacional}

La propuesta de creación de las comisiones de investigación fue una iniciativa rusa en el seno de la Conferencia de la Haya de 1899. La misión de las comisiones de investigación es la de establecer la materialidad de los hechos ocurridos, origen de la desavenencia. Existen unas reglas de funcionamiento de estas comisiones:

1) La investigación tendrá carácter contradictorio.

2) La Comisión puede trasladarse temporalmente a los sitios que crea conveniente como medio de información. 
3) Puede solicitar de cualquiera de las partes las explicaciones o informes que considere convenientes.

4) Las partes se comprometen a procurar a la Comisión todos los medios y facilidades necesarias para que puedan conocer exactamente los hechos.

5) Las deliberaciones serán secretas.

6) El informe de la Comisión será firmado por todos sus miembros y leído en sesión pública, en presencia de las partes.

7) El informe no tiene carácter de sentencia arbitral. Se limita a comprobar los hechos.

La creación de las comisiones de investigación tiene carácter voluntario. Las comisiones de investigación fueron utilizadas en diversos casos por la Sociedad de Naciones, y más recientemente por la O.N.U. y por el Consejo de Europa, donde se utilizan frecuentemente en el ámbito de la protección de los derechos humanos. Como ha ocurrido recientemente con la Comisión de investigación sobre la utilización de armas químicas en la guerra Irán- Irak en 1987-2003, o sobre los crímenes contra la humanidad cometidos en la antigua Yugoslavia en 1902, y en Ruanda en 1994.

\section{d) La conciliación internacional}

Puede definirse como "la intervención en el arreglo de una diferencia internacional, de un órgano sin autoridad política propia que, gozando de la confianza de las partes en litigio, está encargado de proponer una solución que no es obligatoria para las partes". Las misiones de las comisiones de conciliación son triples:

a) Determinación de los puntos de hecho.

b) Fijación de los puntos de Derecho.

c) Informe de la Comisión con una propuesta de solución de la diferencia.

La diferencia entre las comisiones de investigación y las comisiones de conciliación está en que en las primeras no se formulan propuestas de arreglo, sino que se limitan a la fijación de los hechos.

La conciliación internacional está reglamentada en numerosos tratados bilaterales y multilaterales. Un ejemplo es el Acta General para el Arreglo Pacífico de las Diferencias Internacionales, adoptada por la Asamblea General de la Sociedad de Naciones, en 1928, y revisada por la Asamblea General de las Naciones Unidas, en 1949. De esta Acta, básica en la materia, destacamos las características de la conciliación: 
1) Pueden ser sometidas al procedimiento de conciliación las diferencias de cualquier naturaleza.

2) Las comisiones tendrán carácter permanente o bien especial cuando se constituyan por las partes en litigio para la solución de este.

3) Las comisiones permanentes se constituyen en el plazo de seis meses a petición de una de las partes.

4) Estarán compuestas de cinco miembros nombrados por un plazo de tres años y reelegibles.

5) Las comisiones actúan mediante demanda.

6) Se reunirán en la sede de NNUU o en un lugar designado por el Presidente.

7) Los trabajos no serán públicos, salvo decisión de la Comisión con asentimiento de las partes.

8) El procedimiento será contradictorio.

9) La misión de la Comisión es intentar conciliar a las partes.

10) Los trabajos de la Comisión finalizan mediante un acta en la que debe constar si las partes han llegado o no a un acuerdo, y las condiciones del mismo, si lo hubiere. Esta acta se comunicará a las partes, que podrán decidir sobre su publicación

\section{e) El arbitraje internacional}

\section{Ideas generales}

Una controversia surgida entre sujetos internacionales puede ser sometida por estos a un tercero independiente para que adopte, después de un procedimiento contradictorio, una decisión fundada en derecho obligatoria para las partes por la que se ponga fin a la misma. Estaremos en estos casos ante los denominados medios jurídicos de solución pacífica de diferencias, que son dos:

- El arbitraje internacional

- El arreglo judicial

El arbitraje internacional es una institución jurídica de gran tradición histórica, que ha cumplido una importante función al servicio de la paz y de la justicia a lo largo de los tiempos y que pervive en la actualidad, desarrollándose principalmente en el ámbito de las soluciones de controversias fronterizas. 


\section{Evolución histórica}

En la antigua Grecia y en la Edad Media ya aparece la figura del arbitraje. Pero desde el punto de vista internacional no podemos hablar de esta figura hasta el nacimiento del Derecho Internacional Moderno.

El desarrollo del arbitraje, tal y como lo conocemos hoy, se inicia con el Tratado de Amistad, Comercio y Navegación entre Gran Bretaña y EEUU, de 1794, conocido como Tratado Jay, por el que se trata de solucionar los conflictos derivados de la independencia americana. Otro momento importante para la historia del arbitraje fue el llamado Asunto del Alabama, entre EEUU y Gran Bretaña, cuya sentencia se pronuncia en 1872.

La primera Conferencia de Paz de La Haya aprobó en 1899 una Convención Sobre el Arreglo Pacífico de Controversias, en la que se dedicaba todo un título al arbitraje. En la segunda Conferencia de Paz de La Haya de 1907 se revisó la Convención de 1899. El Convenio de La Haya de 1907 todavía está en vigor para más de cincuenta Estados.

La creación de las grandes OOII y del antiguo T.P.J.I. y del actual T.I.J. no ha supuesto la desaparición del arbitraje. Tanto el Pacto de la Sociedad de Naciones como la Carta de NNUU hacen referencia expresa o tácitamente al arbitraje como medio de arreglo de diferencias.

Aunque la historia del arbitraje muestre un paulatino descenso en su utilización, esta tendencia se ha atenuado los últimos tiempos. Así por ejemplo, ocupa un lugar importante entre los medios de solución de diferencias en la Convención de las NNUU sobre el Derecho del Mar de 1982, o en los Convenios de 1969 y 1986 sobre el Derecho de los Tratados.

Además, hay que destacar que la cláusula arbitral figura en numerosos tratados bilaterales. También se están desarrollando, en los últimos tiempos y en el ámbito de las relaciones comerciales internacionales, los llamados arbitrajes transnacionales, para la solución de diferencias relativas a las inversiones que pueden surgir en las relaciones entre personas internacionales y particulares.

Finalmente, hay que citar como otro ejemplo de esta evolución el establecimiento de un Tribunal Arbitral Especial de Reclamaciones Irán - EEUU, fruto de los Acuerdos de Argel de 1981. Este Tribunal está formado por tres salas cuyos miembros son elegidos así: tres por Irán, tres por EEUU y los tres restantes por los seis ya elegidos.

\section{Concepto y caracteres}

El arbitraje es un medio de solución de las diferencias entre sujetos internacionales en el que interviene un tercero independiente (órgano unipersonal o colegiado) al que las partes 
de mutuo acuerdo han investido de la facultad de adoptar, después de un procedimiento contradictorio, una decisión basada en Derecho y jurídicamente obligatoria para las mismas. Son características principales del arbitraje:

1) El consentimiento de los Estados, sin el cual no es posible someter una controversia al arbitraje

2) Se busca siempre una solución basada en el Derecho. Excepcionalmente, las partes pueden acordar resolver sobre la base de la equidad. Se trata de arbitrajes más políticos que jurídicos

3) Los jueces son elegidos por las partes en litigio. No están predeterminados como en el arreglo judicial.

4) Carácter obligatorio de la sentencia. El arbitraje internacional no está limitado solo a los Estados, sino que también las OOII gozan de capacidad en este sentido. Arbitrajes transnacionales son aquellos en los que junto a los sujetos internacionales intervienen también particulares.

\section{Fundamento}

Es esencial el consentimiento de las partes para que se constituya el Tribunal o Comisión Arbitral y emita una sentencia obligatoria para las partes. El arbitraje debe ser voluntariamente aceptado y ningún Estado puede ser obligado a someterse al juicio arbitral.

La sumisión al arbitraje se contiene:

- En un acuerdo internacional único, denominado compromiso arbitral, que será posterior al nacimiento del litigio y destinado a resolverlo;

- O bien en una cláusula compromisoria contenida en un tratado, en la que se establece la obligación de acudir al arbitraje en caso de diferencias en la interpretación del tratado;

- O bien en un tratado de arbitraje, según el cual las partes se comprometen a recurrir al arbitraje para la solución de futuras diferencias

El compromiso es una pieza esencial para el arbitraje en sí. La forma del compromiso está muy elaborada en el Derecho consuetudinario y en el Convencional internacional. Lo normal es que el compromiso se lleve a cabo por medio de un tratado internacional o bien por un acuerdo en forma simplificada mediante cambio de notas. La forma escrita es la comúnmente utilizada. 
Finalmente, es preciso señalar que el tribunal arbitral en tanto que poseedor de la competencia para determinar su propia competencia va a poder interpretar, en el ejercicio de sus funciones, el compromiso arbitral.

\section{El órgano arbitral}

La designación de los árbitros es uno de los derechos de las partes en el arbitraje, salvo que hayan convenido otra cosa al respecto. A veces en el acuerdo de compromiso de arbitraje se especifica que los miembros del Tribunal deben ser obligatoriamente nacionales de terceros Estados. Lo normal es que cada parte nombre uno o dos árbitros, según que el tribunal se componga de tres o cinco miembros, y que el Presidente, llamado superárbitro, se designe por un tercer Estado.

El órgano arbitral es un órgano ad hoc y temporal: se crea para resolver un litigio determinado y desaparece una vez dictada la sentencia. No obstante, en la historia del arbitraje internacional encontramos un ejemplo de un tribunal de carácter permanente.

Órganos temporales permanentes

Entre estos se pueden distinguir tres tipos:

a) El formado por un árbitro único, normalmente un Jefe de Estado. Actualmente es difícil de encontrar, aunque no ha desaparecido.

b) Comisiones mixtas. Formadas por Comisarios designados por las partes entre sus nacionales, soliendo contar con la presencia de un superárbitro llamado a intervenir solo en caso de desacuerdo de los miembros designados por las partes.

c) El Tribunal Arbitral. Es hoy el más frecuente, y está formado generalmente por tres miembros, uno designado por cada parte, y el tercero de común acuerdo entre ellos y buscado entre nacionales de terceros países.

Cuando el órgano arbitral está formado por un Colegio de Árbitros, uno de ellos asume las funciones del Presidente. El Presidente dirige los debates y vela por el respeto del procedimiento. El tribunal estará asistido por un órgano administrativo.

El tribunal suele establecer su sede en un país tercero a la controversia. Se ha utilizado frecuentemente Ginebra y La Haya, y últimamente Nueva York. Respecto a los gastos de funcionamiento, cada parte soportará lo que le corresponda a su delegación, y los gastos comunes serán divididos en partes iguales entre las partes. 


\section{El Tribunal Permanente de Arbitraje}

Tiene su origen en la Conferencia de Paz de La Haya de 1899. No se trata de un verdadero Tribunal, sino de una lista de árbitros y la característica de permanencia no es porque funcione de forma continua, sino porque la secretaría de su sede en el Palacio de la Paz de La Haya funciona permanentemente.

Características del Tribunal Permanente de Arbitraje:

- Su objetivo es facilitar los trámites para constituir el órgano arbitral.

- Tiene su sede en La Haya, donde radica la Oficina internacional, que sirve de Secretaría, la cual tiene por misión transmitir todas las comunicaciones referentes a sus reuniones, custodiar los archivos y gestionar los asuntos administrativos.

- La lista de árbitros, que tienen el título de "Miembros del Tribunal", se forma de la siguiente manera:

- Cada una de las potencias signatarias nombra cuatro personas, como máximo, de reconocida competencia en cuestiones de Derecho Internacional. Estas personas son nombradas por seis años y sus poderes son renovables

- Para constituir el Tribunal, cada parte nombra a dos árbitros (de la lista citada anteriormente), uno solo de los cuales podrá ser nacional suyo. Estos cuatro eligen de común acuerdo un superárbitro. Si hubiera desacuerdo, el superárbitro lo designa una tercera potencia. Si tampoco aquí hubiera acuerdo, se designarán dos Estados para que procedan a la designación. Si aun así tampoco se llegara a un acuerdo, cada parte designará dos candidatos, que serán sorteados. El que gane será el superárbitro.

\section{f) El procedimiento arbitral}

El procedimiento se contiene en el compromiso arbitral. En el Convenio de La Haya de 1907 encontramos unas reglas generales del procedimiento del arbitraje. Una vez designados los árbitros y la sede, se constituye el órgano arbitral, que opera con arreglo a lo siguiente:

- Las partes designan a sus agentes, consejeros y abogados.

- Se distinguen dos fases:

- La escrita: Memoria, Contramemoria, Réplica, Dúplica y los documentos invocados en la causa.

- La oral. Debates ante el órgano arbitral en los que los agentes, abogados o consejeros de las partes exponen las razones alegadas. 
- Las partes tienen derecho a promover excepciones o incidentes procesales.

- Los miembros del órgano arbitral pueden preguntar a los agentes o consejeros y pedirles aclaraciones de los puntos dudosos.

- Una vez los consejeros y agentes han presentado las aclaraciones y pruebas escritas y orales, el Presidente declara concluidos los debates.

- Las deliberaciones del órgano arbitral son a puerta cerrada y secretas. Las decisiones se toman por mayoría.

- La sentencia será motivada, leída en sesión pública y decidirá la cuestión definitivamente sin apelaciones.

- La interpretación y ejecución de la sentencia será sometida al juicio del órgano arbitral que la ha dictado.

- La sentencia solo es obligatoria para las partes en litigio.

\section{g) La sentencia arbitral y los recursos contra la misma}

La sentencia se redacta por escrito y contiene generalmente una exposición de motivos de hecho y jurídicos y una parte dispositiva o fallo propiamente dicho. La misma se firma por todos los árbitros o bien por el Presidente y el que ejerza funciones de secretario. Los árbitros que disientan de la motivación o del fallo pueden adjuntar su voto particular.

La sentencia firme obliga a los Estados Partes a ejecutarla de buena fe, adoptando los medios necesarios para asegurar sus efectos. En la práctica internacional, excepcionalmente algún Estado parte se ha negado a ejecutar la sentencia. Para ello ha alegado los vicios que según él afectaban la sentencia. Contra la sentencia no cabe recurso de apelación o casación, pues no hay tribunal u órgano superior, salvo que así se acuerde entre las partes. Por ejemplo, se puede acordar someter la sentencia a la apreciación del T.I.J.

No obstante, caben tres tipos de recursos:

- De aclaración: en caso de desacuerdo de las partes sobre el verdadero sentido de la sentencia, como el que planteó Inglaterra respecto de la sentencia de 1977 en el asunto de la delimitación de la plataforma continental entre Francia y el Reino Unido, que dio lugar a una sentencia interpretativa.

- De reforma: en los supuestos en que el árbitro haya cometido exceso de poder resultante del compromiso o haya habido un defecto grave de procedimiento, como el que se había producido, según Guinea-Bissau, en el asunto que le enfrentaba a Senegal en relación con la delimitación de sus espacios marítimos. 
- De revisión: cuando después de pronunciar la sentencia apareciera un hecho nuevo que, de haberse conocido antes, hubiera ejercido una influencia definitiva en la misma o cuando se determinara que la sentencia es en parte o en todo consecuencia de un error de hecho que resulta de las actuaciones o documentos en causa (como argumentó Chile en su solicitud de revisión, y en subsidio de interpretación, respecto de la sentencia en el asunto de la Laguna del Desierto).

\section{h) El Tribunal Internacional de Justicia}

\section{Antecedentes}

A principios del s. XX comenzaron los intentos de institucionalizar la justicia internacional creando órganos de arreglo judicial de carácter permanente y por tanto capaces de juzgar de inmediato los asuntos que les fueran sometidos.

En la II Conferencia de la Paz en la Haya de 1907, los EE.UU. propusieron crear un Tribunal de Justicia de carácter permanente distinto del llamado Tribunal Permanente de Arbitraje; sin embargo, la propuesta no fue adoptada.

La Conferencia de la Paz Centroamericana culminó con la firma en 1907 de la Convención para el establecimiento de una Corte de Justicia Centroamericana que concluyó tras la experiencia fructuosa de diez años y habiendo conocido diez casos que le fueron sometidos.

\section{El Tribunal Permanente de Justicia Internacional}

Al término de la Primera Guerra Mundial, la Conferencia de la Paz de París creó el Tribunal Permanente de Justicia Internacional. El Consejo de Naciones designó una Comisión de Juristas -llamado Comité de los Diez- que preparó el proyecto del Estatuto del Tribunal Permanente aprobado en 1920.

Al comienzo de la Segunda Guerra Mundial, eran parte en el Estatuto del T.P.J.I. cincuenta de los sesenta y ocho Estados independientes que formaban la comunidad internacional en aquel momento.

\section{Los tribunales internacionales tras la segunda guerra mundial}

Hoy los tribunales internacionales han proliferado. Entre ellos nos encontramos con uno de competencia internacional -el Tribunal Internacional de Justicia—y otros de competencia específica, entre los que cabe señalar el Tribunal Europeo de Derechos Humanos, con sede en Estrasburgo, y la Corte Internacional de Derechos Humanos, con sede en San José de Costa Rica. 
También merecen mención los tribunales creados a principios de los años noventa para el enjuiciamiento de los presuntos responsables de violaciones graves del Derecho Internacional Humanitario cometidas en el territorio de la antigua Yugoslavia y en Ruanda.

También ha sido creados: la nueva Corte Penal Internacional, cuyo estatuto fue adoptado y abierto en 1998 y promulgado en el 2003; el Tribunal de las Comunidades Europeas, con sede en Luxemburgo; los tribunales de ciertas organizaciones internacionales, como la Unión Postal Universal y la Organización de la Aviación Civil Internacional.

Existen tribunales administrativos que no juzgan controversias entre Estados sino entre los funcionarios y la Organización Internacional en la que prestan sus servicios. Cabe señalar que esta proliferación de tribunales, a la que estaba desacostumbrado el orden internacional, ha llegado a despertar alguna inquietud en torno a si podría representar algún peligro para la unidad del Derecho Internacional. Sin embargo, no solo debe verse como un signo de la relativa madurez que vive el Derecho Internacional, sino como un importante estímulo que puede contribuir a su avance.

\section{Creación del Tribunal Internacional de Justicia}

El nacimiento del TIJ está ligado al de la Organización de las Naciones Unidas, de la cual es el órgano judicial principal. Sus vínculos con las N.U. hicieron necesaria la creación de un tribunal de justicia nuevo y distinto del Tribunal Permanente de Justicia Internacional, que había sido una creación de la fracasada y extinguida Sociedad de Naciones.

La creación de un nuevo tribunal se previó por la Conferencia de Dumbarton Oaks, de 1943, la cual propuso que el Estatuto del futuro tribunal formara parte integrante de la Carta de la Organización y que los Estados miembros fueran parte integrante ipso facto de la Carta. Se aprobó el Estatuto en la Conferencia de San Francisco el día 6 de junio de 1945. Su sede está en La Haya, y tiene su propio Reglamento.

\section{Organización del Tribunal Internacional de Justicia}

El Tribunal Internacional de Justicia no solo es un órgano principal de las Naciones Unidas sino que tiene funciones de órgano colectivo de carácter judicial, compuesto por un cuerpo de magistrados o jueces y de un Secretario. Está organizado de forma que pueda funcionar de manera permanente, según lo dice el art. 23 de su Estatuto.

Está compuesto por 15 miembros, que forman un cuerpo de magistrados independientes, elegidos entre personas que gocen de alta consideración moral y que reúnan las condiciones requeridas para el ejercicio de las más altas funciones judiciales. En la elección también se tendrá en cuenta, además de los requisitos señalados, que en el conjunto estén representadas 
las grandes civilizaciones y los principales sistemas jurídicos del mundo. La lista de candidatos a jueces se forma en base a propuestas hechas por los grupos nacionales del Tribunal Permanente de Arbitraje.

La elección de los jueces se hace por la Asamblea General y el Consejo de Seguridad de las Naciones Unidas, que votarán independientemente. Ello quiere decir que el candidato debe tener la mayoría requerida en los dos órganos reseñados. La duración del mandato de los jueces es de 9 años, y son reelegibles.

Existe en el TIJ la figura del juez ad hoc, prevista para las cusas en que no haya ningún juez que tenga la nacionalidad de los Estados litigantes. En este caso, está prevista la posibilidad de designar un magistrado por el Estado o Estados que no tienen juez de entre sus nacionales en el Tribunal, mientras dure el procedimiento.

El Presidente se elige por tres años y representa al Tribunal, dirige los trabajos, los servicios, los debates y las vistas; su voto tiene calidad en caso de empates. Puede ser sustituido por el vicepresidente en los casos previstos.

La Secretaría del Tribunal está formada por un Secretario, el Secretario Adjunto y los funcionarios.

El Tribunal se reúne y funciona en Pleno, en salas especiales o en sala de procedimiento sumario. En Pleno es necesaria al menos la presencia de nueve miembros. La iniciativa puede partir del propio Tribunal o de las partes hasta el final del procedimiento.

Finalmente, la sala de los procedimientos sumarios está prevista en el art. 29 del Estatuto. La misma se constituirá anualmente por cinco magistrados y puede, a petición de las partes, oír y fallar los asuntos sumariamente.

\section{La competencia contenciosa del Tribunal}

Según el D.I., la iniciación de un procedimiento no es posible por la voluntad de uno solo de los contendientes. El consentimiento es una pieza esencial del procedimiento internacional, pues, como ha sido señalado, "la justicia internacional es facultativa y la competencia del Tribunal continúa fundada sobre el consentimiento de los Estados".

Analizamos la competencia contenciosa del Tribunal, y para una mayor claridad distinguiremos entre competencia ratione personae y competencia ratione materiae.

a) Con respecto a las personas (ratione personae), hay que afirmar que "solo los Estados podrán ser partes en los casos ante la Corte". Las personas físicas y jurídicas no tienen acceso al 
Tribunal en la vía contenciosa ni en la consultiva. Tampoco las organizaciones internacionales. Sin embargo, y tal y como lo establece el mismo artículo 34 del Estatuto, el Tribunal "podrá solicitar de las organizaciones internacionales públicas informaciones relativas a casos que se litiguen ante la Corte, y recibirá la información que dichas organizaciones envíen a iniciativa propia”. El Tribunal está abierto a los Estados, pero no a todos los Estados. Cabe al respecto distinguir los siguientes grupos que pueden llevar sus diferencias ante al Tribunal:

1) Los Estados que sean parte en el Estatuto del Tribunal, entre los que se distinguen dos grupos: los Estados que sean miembros de las N.U., ya que estos son ipso facto partes en el Estatuto de la Corte Internacional de Justicia, y otros Estados que han llegado a ser partes del Estatuto por cumplir las condiciones que determine en cada caso la Asamblea General a recomendación del Consejo de Seguridad.

2) También está abierto el Tribunal a los Estados que no sean parte en el Estatuto, en virtud del artículo 35.2 del mismo y en las condiciones que fueron fijadas por el Convenio de Seguridad en su Resolución 9 (1946). Dichas condiciones son: comprometerse a cumplir de buena fe la decisión o decisiones del Tribunal y aceptar todas las obligaciones de los miembros de las N.U. en virtud del art. 94 de la Carta

b) Por razón de la materia (rartione materiae), el Tribunal es competente para entender de todas las diferencias de orden jurídico que les sean sometidas por los Estados parte en las mismas. Para que el T.I.J ejerza su competencia en materia contenciosa, es necesario que las partes en la diferencia hayan manifestado su voluntad de someter el asunto al Tribunal.

Para la aceptación de la jurisdicción del Tribunal encontramos una diversidad de formas:

- Por medio de un compromiso,

- Por medio de tratados o convenios vigentes, en los que se prevé el sometimiento al Tribunal para todos los casos que se presenten en el futuro. Existen numerosos tratados en los que se prevén esas cláusulas compromisorias.

- Por la cláusula facultativa. Así, el art. 36.2 del Estatuto del T.I.J prevé que "los Estados partes en el presente Estatuto podrán declarar en cualquier momento que reconocen como obligatoria ipso facto y sin convenio especial, respecto de cualquier otro Estado que acepte la misma obligación, la jurisdicción de la Corte en todas las controversias de orden jurídico que versen...”. Una buena parte de la doctrina ha mantenido que la aceptación de la cláusula facultativa supone un acto unilateral. Las declaraciones de los Estados adhiriéndose a la cláusula facultativa pueden hacerse incondicionalmente o bajo condición de reciprocidad por parte de varios Estados o por determinado tiempo. 
- Por el principio del forum prorrogatum. Se trata de un concepto jurídico procesal perfectamente determinado y construido dentro de la teoría procesal interna que ha sido recogido por el D.I.

\section{La competencia consultiva del Tribunal}

Es la facultad de emitir dictámenes respecto de cualquier cuestión jurídica, según el artículo 65 del Estatuto. Sobre quien puede pedir los dictámenes al Tribunal, hay que decir que:

- Los Estados no pueden.

- Sí pueden hacerlo las organizaciones internacionales.

Como puede observarse, ocurre lo contrario con respecto a la competencia contenciosa, es decir, a la facultad de emitir sentencias.

Los Estados no pueden pedir dictámenes al T.I.J., pero sí pueden intervenir ante el Tribunal mediante exposiciones escritas y orales.

La Asamblea General y el Consejo de Seguridad tienen derecho, así como otros órganos de las Naciones Unidas y los organismos especializados de la misma que sean autorizados, a pedir dictámenes al TIJ, según el art. 96 de la Carta de las Naciones Unidas.

El T.I.J. respecto a la competencia ratione materiae es competente en vía consultiva solo para pronunciarse sobre cualquier cuestión jurídica, según los art. 65 de su Estatuto y 96 de la Carta. Quedan fuera las cuestiones políticas y de hecho. El dictamen puede versar sobre una cuestión concreta o bien sobre una formula en términos abstractos. 


\section{CONCLUSIONES}

- El Derecho Internacional es una disciplina que regula las relaciones jurídicas de entes soberanos no subordinados a ningún poder superior.

- No existe en el sistema internacional un poder central que determine cuál debe ser la conducta de los Estados, pero la historia mundial, por necesidad, ha establecido la creación de una Asamblea, común para todos, para debatir y deliberar asuntos de interés mundial, básicos para preservar la concordia entre las diversas unidades estatales.

- Toda norma de ius cogens es una norma imperativa con efecto jurídico universal, que no admite acuerdo en contrario, salvo una modificación ulterior del mismo rango y fuerza.

- El Pacta Sunt Servanda es un principio de Derecho Internacional, el cual establece que el acuerdo suscrito entre las partes se debe cumplir sobre una base de conciencia jurídica, es decir, los pactos se cumplen en función de la intención de los Estados y su voluntad por suscribirlos.

- La buena fe es un principio de categoría subjetiva que tiene un cauce objetivo en su materialización, y el cual se vincula con el Pacta Sunt Servanda, ya que ambos ayudan a cumplir los pactos de manera ordenada, pacífica, conscientes de las relaciones internacionales de los propios Estados.

- Es necesario reconocer que los instrumentos internacionales son mutables, ya que la historia es cambiante. Para ello, las partes involucradas deben reconocer que los hechos que generaron algún tratado deben proceder de común acuerdo y de buena fe, para evitar controversias.

- La solución de controversias internacionales alcanza también una categoría de ius cogens, ya que el espíritu de la legislación internacional versa sobre paradigmas éticos que permiten a los Estados dirigirse de manera armónica para evitar los conflictos propios del sistema internacional. 


\section{REFERENCIAS}

- Carrillo Salcedo, J .A. Soberanía del Estado y Derecho Internacional. Madrid: 1976.

- Clausewitz, Carl. De la Guerra. Buenos Aires: Ediciones Mar Océano, 1960. Traducida por R.W. de Setaro.

- CIJ. Caso Barcelona Traction. 1970, p. 31.

- Coser, Lewis. Las funciones del conflicto social. México: Fondo de Cultura Económica, 1961.

- E. Suy. "Sur la définition du Droit des Gens". En : R.G.D.I., octubre-diciembre, 1960.

- Ferrero Rebagliati, Raúl. Derecho Internacional. Tercer Mundo. Temas de Derecho Internacional. Lima, 1989.

- Jiménez de Arrechaga, Eduardo. Derecho Internacional contemporáneo. Madrid: Tecnos, 1980.

- Maúrtua de Romaña, Óscar. "Pacta Sunt Servanda y la solución de controversias". Rev. $A D P$. No 37, julio-setiembre, Lima, 1994.

- Pastor Ridruejo, José Antonio. Curso de Derecho Internacional Público y organizaciones internacionales. 8va Ed. Madrid: Tecnos, 2001.

- Real Academia Española. Diccionario de La Lengua Española. 19a. Edición. Madrid: Editorial Espasa-Calpe, 1970.

- Truyol y Serra, Antonio. La Sociedad Internacional. Madrid: Alianza Editorial, 2008.

- Yaseen, Mustafá. Anuario de la Comisión de Derecho Internacional. Vol. I.

- Wieland Alzamora, Hubert. Manual del diplomático. Lima: Fondo de Cultura Económica, Academia Diplomática del Perú, 1999. 